Original Research Paper

\title{
Effect of Styrofoam Waste Feeds on the Growth, Development and Fecundity of Mealworms (Tenebrio molitor)
}

\author{
Nismah Nukmal, Suratman Umar, Sheila Puspita Amanda and Mohammad Kanedi \\ Department of Biology, Faculty of Mathematics and Sciences, \\ University of Lampung, Jl. Sumantri Brojonegoro No. 1, Bandar Lampung, Indonesia
}

\author{
Article history \\ Received: 18-09-2017 \\ Revised: $27-11-2017$ \\ Accepted: 28-12-2017 \\ Corresponding Author: \\ Mohammad Kanedi \\ Department of Biology, Faculty \\ of Mathematics and \\ Sciences,University of \\ Lampung, Jl. Sumantri \\ Brojonegoro No. 1,Bandar \\ Lampung, Indonesia \\ Email: wegayendi@yahoo.com
}

\begin{abstract}
It has been reported that Styrofoam can be biodegraded by Tenebrio molitor beetle larvae within a retention time of less than $24 \mathrm{~h}$ and the larvae fed solely with Styrofoam able to survive for more than a month. The question is whether Styrofoam can be used as an economical feed in the cultivation of mealworms? To determine productivity effect of Styrofoam feeds on mealworms, the larvae $(n=120)$ were grouped into three. Group 1, 2 and 3 were cosecutively fed with yeasts (as the standard diet), Expanded Polystyrene (EPS) and Extruded Polystyrene (XPS) were used. The observations take place in two stages. At stage 1, measurements were made on percent survival of the caterpillar, larval weight, prepupal periods, pupation periods, pupal weight and imago weight. At stage 2, the imago emerged from the pupae were separated between males and females and then mated. The number of eggs laid by the imago females in ten days are noted. The results showed, in comparison to the standard diet, EPS and XPS foam feeds did not give a significant effect on the mortality of the larvae. Both types of Styrofoam promote a significant longer periods of prepupal and pupation and significantly reduce number of eggs. Compared with yeasts and EPS foam, only XPS showed a lower weight of larvae, pupae and imago. It is inferred that the Styrofoam is not worthy as economical feeds in mealworms cultivation. However, given that Styrofoam feeds can maintain the insects life and produce eggs, the use of mealworms in polystyrene foam waste degradation is still worth considering.
\end{abstract}

Keywords: Mealworms, Tenebrio molitor, Styrofoam, Polystyrene Foam

\section{Introduction}

Styrofoam refers to the expanded Polystyrene (PS) foam commonly used for food and beverage containers such as disposable cups and boxes, or cushioning material in packaging. Due to its low recycling rate, polystyrene has polluted environment, causing serious threat to both wildlife and human health. In the environment, polystyrene foam debris are easily mistaken for food and end up ingested by wildlife that can cause harms (ATSDR, 1992; CIWMB, 2004; Lacounty Gove, 2008). Styrene oxide, the reactive metabolite of styrene, known to shows positive carcinogenic results in oral exposure bioassays (WHO, 1987).

Various efforts to eliminate and recycle styrofoam waste has been done, such as by burial (land fill), incineration and use of plastic degrading microbes. However, burial (without contamination, lack of UV and oxygen) make the foam more stable and has long degradation times. Whereas incineration requires high temperatures (high energy needed) to combust properly (Derrick, 2010). On the other hands, there is no biodegradation technique found to have practical application, thus it is recommended to screen efficient organisms and developing technologies capable of degrading plastic efficiently without affecting environment (Kale et al., 2015).

Later, there is an exciting hope for PS waste degradation after Yu Yang and colleagues published their highly valuable and promising research findings that PS foam can be biodegraded by $T$. molitor beetle larvae, the mealworms. As reported, the styrofoam was efficiently degraded in the larval gut within a retention time of less than $24 \mathrm{~h}$ and the larvae fed solely with styrofoam was able to survive for more than a month, the same as larvae that fed with standard diet (Yang et al., 2015a). Antibiotics test results against gut bacterial activities of the larvae indicated that gentamicin-feeding mealworms lost 
the ability to depolymerize PS and mineralize PS into $\mathrm{CO}_{2}$. It can be inferred that the ability of the mealworms in biodegradation of styrofoam was due to the role and activity of gut bacteria (Yang et al., 2015b).

Given T. molitor is a cultivated insect and has great economic value, such research findings also promise benefits for the mealworms breeders. As has been indicated, the farming of edible insects is an alternative strategy for the production of protein-rich food and feed with a low ecological risk (Grau et al., 2017). In the process of cultivation, like any other livestock business, mealworms breeding also requires feed. In Indonesia, mealworms $T$. molitor are normally fed with wheat pollard or fermented cassava yeasts causing high cost in the cultivation process (Sitompul, 2006). Especially for yeast, fruit fly larvae (Drosophila melanogaster) feeding on grape berries inoculated with baker yeast found show high percentage of survival (Becher et al., 2012).

If the polystyrene foam waste can indeed be consumed by mealworms certainly the cultivation cost of the caterpillar can be minimized. To determine productivity effect of PS foam feeds on mealworms, the growth, developmental and reproductive parameters of the larvae fed with Styrofoam waste have been investigated. In order to find out whether the types of Styrofoam are influential then in this study Expanded Polystyrene (EPS) and Extruded Polysterene (XPS) were used. Such research statement was based on the facts that, physically, XPS foam has higher density and compressive strength than that of EPS (Graham, 2015).

\section{Materials and Methods}

\section{Polysterene Foam}

The polystyrene foam used in this study were Expanded Polystyrene (EPS) and Extruded Polystyrene (XPS). EPS foam waste of electronic equipment boxes were collected from electronics stores, whereas XPS foam were bought from food-trays shop in the city of Bandar Lampung, Indonesia. Before being provided to the mealworms, the foam was washed using distilled water and chopped into small cubes with the size of each side ranging from 3 to $5 \mathrm{~mm}$.

\section{Mealworms}

Caterpillars of $T$. molitor beetle used in this experiment were purchased from a mealworms farm in the city of Bandar Lampung, Lampung, Indonesia. The larvae (about 1,500) consists of instar 4-5 were reared in plastic boxes (width: $12 \mathrm{~cm}$, length: $32 \mathrm{~cm}$, height: $9 \mathrm{~cm}$ ) at room temperature and fed ad libitum with standard diet (fermented cassava yeasts).

\section{Study Design and Treatments}

The larvae of mealworms $(n=120)$ that have been acclimatized for one week were taken from the stock tray and separated into three groups (40 larvae each). Group 1, 2 and 3 were consecutively fed with yeasts, EPS foam and XPS foam.

\section{Experimental Stages and Parameters}

This experiment was carried out in two stages. The first tage is to measure the effect of treatments on survival, growth and development of larvae. At this stage, measurements were made on percent survival of the caterpillars, larval weight, prepupal period, pupation period, pupal weight and imago weight. Prepupal period is defined when caterpillar enters a nonfeedingwandering stage, while pupation period is defined when the prepupa totally immobile and encloses itself in a pupal case (Sreeramoju et al., 2016). The second stage is to find out whether treatments affect fecundity of the mealworms. For that, the hatching imago of the pupae (from stage 1 experiment) were separated between males and females. Next, the males and females are mated and then the number of eggs produced by the females in ten days were calculated.

\section{Data Analysis}

Goodness of Fit Test $\left(\chi^{2}\right)$ was used to test survival rate of the insect. Anova dan LSD test were used to compare mean value of other parameters.

\section{Results}

\section{Survival Rate}

The effect of standard feeding, EPS foam and XPS foam on the survival of mealworms from larval to imago stages is presented in Table 1 . Test of goodness of fit (Chi square test) to the data yielded $\chi^{2}=0.1619(\mathrm{df}=6$, $\alpha=0.05$ ). Considering $\chi^{2}$ crit for the $\mathrm{df}=6$ and $\alpha=0.05$ is 14.449 , it is suggested that the EPS and XPS foam feeds do not give a significant effect on the mortality of mealworms T. molitor.

\section{Growth and Development}

Table 2 indicates effects of feeding treatments on the growth and development of the larvae and pupae of mealworms $T$. molitor. The initial mean weight of larvae (instar 4-5) subjected to treatments has the same variance $(p>0.05)$. At the final instar stage, all larvae were able to grow but the growth parameters of the mealworms fed on XPS foam showed a lower weight compared with the larvae fed on yeasts and EPS foam $(p<0.05)$. The prepupal mean periods passed by the mealworms fed with styrofoam is longer than that of larvae fed on standard diet $(p<0.000)$, but there is no difference between EPS and XPS foam $(\alpha=0.05)$. Similar to the prepupal periods, the pupation periods of the mealworms fed with styrofoam was also longer than that of group fed fed on yeasts $(p<0.000)$, however between EPS and 
XPS is no significant difference ( $\alpha=0.05$ ). Next, pupal weight measurements showed that mealworms fed on XPS foam tended to have lower pupal weights than groups fed with yeasts and EPS foam $(\mathrm{p}<0.05)$, however EPS foam did not show significant effects compared with teh standard diet $(\alpha=0.05)$.

\section{Fecundity}

Mean weight of new beetles emerged from the pupae (the imago) of T. molitor treated with standard diet and styrofoam waste and the mean number of eggs laid by the females that have been mated male imago are presented in Tabel 3. Anova results of the mean weight of the imago showed a significant variance $(\mathrm{p}<0.05)$, but the LSD test results $(\alpha=0.05)$ indicated that only mealworms given XPS whose imago weight significantly lower than that of fed with the standard diet. While the caterpillar given EPS did not show significant weight differences with the yeasts or XPSfed groups. Furthermore, the number of eggs produced by imago of mealworms fed with both type of styrofoam is significantly less than that produced by imago that develops from caterpillars fed on yeast, but there is no significant difference between the EPS and XPS groups $(\alpha=0.05)$.

\section{Discussion}

Based on the data in Table 1 it can be asserted that PS foam waste is eatable and non-lethal to the larvae of T. molitor beetle. Current findings seem to confirmed what were reported that the mealworms fed solely styrofoam able to survive for a month. Such ability of the mealworms in biodegradation of styrofoam was due to the role and activity of gut bacteria (Yang et al., $2015 \mathrm{a} ; 2015 \mathrm{~b})$. There are at least a dozen genera of bacteria have been identified from the gut of mealworms such as Spiroplasma, Weissella, Lactococcus, Rahnella, Cronobacter, Enterococcus, Lactobacillus, Bacillus, Enterobacter, Clostridium and Pantoea 13 (Wang and Zhang, 2015). Some Spiroplasma species that are known to be insect pathogens, even did not cause any harmful effects on the T. molitor larvae (Jung et al., 2014). In addition, the non-lethal effect of the styrene foam in mealworms is allegedly due to detoxifying role of some gut microbiota of the insect (Genta et al., 2006).

In the gut of Tenebrionidae beetles in which $T$. molitor is included, in fact, not only bacteria might exist but also various other microbes such as fungi and yeast. Hypocreales, Xylariales, Capnodiales Botryosphaeriales, Pleosporales, Saccharomycetales and Chaetothyriales are among the fungi taxa that have been isolated from these beetles (Rojas-Jiménez and Hernández, 2015). In insect nutrition, it was revealed that in the absence of yeast associates, the insect performance decrease (Vega and Dowd, 2005).

Though polystyrene foam feeds did not show lethal effect, but as shown in Table 2 and 3, the PS foam waste clearly affects growth, development and reproduction of the mealworms. In comparison to the standard diet and EPS foam, XPS feedings showed the worst results mainly for larval weight, pupal weight and imago weight. There are several scientific reports that can be explained as to why standard feed, especially yeast, is capable of producing better productivity effects on larvae. Yeast cells are sources of B vitamins, proteins, trace metals and amino acids that could be easily assimilated through simple digestion. Additionally, yeasts contain $7.5-8.5 \%$ nitrogeny dry weight, so that the yeasts can be a better source of nitrogen and other dietary requirements (Gibson and Hunter, 2010).

Table 1: Survival rate of mealworms T. molitor fed with standard and styrofoam feeds

\begin{tabular}{llll}
\hline & Feeds types & & \\
Variables & Yeasts n (\%) & EPS foam n (\%) & XPS foam n (\%) \\
\hline Number of larvae & $40(100)$ & $40(100)$ & $40(100)$ \\
Number of prepupae & $37(92.5)$ & $37(92.5)$ & $35(87.5)$ \\
Number of pupae & $37(92.5)$ & $37(92.5)$ & $33(82.5)$ \\
Number of imago & $34(85.0)$ & $34(85.0)$ & $32(80.0)$ \\
\hline
\end{tabular}

Table 2: Growth and development of mealworms T. molitor fed with standard and styrofoam feeds

\begin{tabular}{llll}
\hline & Feeds types & & \\
& - & & \\
Variables & Yeasts (mean \pm SE) & EPS foam (mean \pm SE) & XPS foam (mean \pm SE) \\
\hline Initial larval weight (mg) & $60.08 \pm 1.44^{\mathbf{a}}$ & $59.14 \pm 1.64^{\mathbf{a}}$ & $60.21 \pm 1.96^{\mathbf{a}}$ \\
Final larval weight (mg) & $195.5 \pm 4.02^{\mathbf{a}}$ & $188.0 \pm 2.94^{\mathbf{b}}$ & $183.75 \pm 2.23^{\mathbf{b}}$ \\
Prepupal period (days) & $2.43 \pm 1.34^{\mathbf{a}}$ & $5.37 \pm 1.94^{\mathbf{b}}$ & $5.05 \pm 2.34^{\mathbf{b}}$ \\
Pupation period (days) & $7.23 \pm 2.77^{\mathbf{a}}$ & $10.88 \pm 3.33^{\mathbf{b}}$ & $11.6 \pm 3.05^{\mathbf{b}}$ \\
Pupal weight (mg) & $180.0 \pm 8.29^{\mathbf{a}}$ & $171.08 \pm 7.71^{\mathbf{a}}$ & $141.35 \pm 9.87^{\mathbf{b}}$ \\
\hline
\end{tabular}

$(\overline{\mathbf{a}, \mathbf{b}, \mathbf{c}})$ Mean values with different superscripts within the same row differ significantly $(\mathrm{p}<0.05)$ 
Table 3: Imago weight and fecundity of mealworms T. molitor fed with standard and styrofoam feeds

\begin{tabular}{|c|c|c|c|}
\hline \multirow[b]{2}{*}{ Variables } & \multicolumn{3}{|l|}{ Feeds types } \\
\hline & Yeast (mean \pm SE) & EPS foam $($ mean \pm SE $)$ & $\mathrm{XPS}$ foam $($ mean $\pm \mathrm{SE})$ \\
\hline Imago weight (mg) & $144.11 \pm 8.77^{\mathrm{a}}$ & $132.06 \pm 8.06^{\mathrm{ab}}$ & $116.87 \pm 7.77^{b}$ \\
\hline Number of eggs & $46.5 \pm 2.77^{\mathrm{a}}$ & $28.9 \pm 1.90^{\mathrm{c}}$ & $31.80 \pm 2.45^{\mathrm{bc}}$ \\
\hline
\end{tabular}

$\left({ }^{\text {a. }} \mathbf{b . c}\right)$ Mean values with different superscripts within the same row differ significantly $(\mathrm{p}<0.05)$

Regarding the low number of eggs produced by mealworms fed PS foam, it seems a logical consequence of the low rate of growth and development of larvae, pupae and imago itself. As reported by Young-Kyu Park and colleagues, it was revealed that fecundity of $T$. molitor was significantly affected by the pupal weight (Park et al., 2012) and might also related to the adult weight (Morales-Ramos et al., 2012).

Another thing that is not less important revealed in this study is that XPS foam provides less productivity measures compared to EPS foam feeds. This may be related to the physical and chemical aspects differences between EPS foam and XPS. EPS foam known to have a higher rate of permeability, contains up to $15 \%$ recycled content, has never contained HFCs, CFCs, HCFCs, formaldehyde, or color dyes (ACH, 2013). HCFCs, as one example, was known to not only reduce body weight but also cause microscopic liver lesions in laboratory mammals (WHO, 2000). Formaldehyde is another chemical content in XPS foam that is allegedly responsible for low productivity in mealworms. Formaldehyde solution is known to be common strategy used to control microbial growth in many insect diets and effectively caused decrease in the microbial development (Roeder et al., 2010).

Although PS foam feed proved unable to match the productivity effects of standard diets on the growth, development and reproduction of $T$. molitor beetle but the use of mealworms for the purpose of polystyrene waste biodegradation, especially when combined with other biodegradation techniques, is quite promising. There are many laboratory and field tests indicate that some soil microbes able to degrade PS foam to an adequate level. Pseudomonas aeruginosa, Bacillus subtilis, Staphylococcus aureus, Streptococcus pyogenes and Aspergillus niger are examples among soil inhabitants bacteria proven to decrease various types of plastic waste including PS foam (Asmita et al., 2015). Other soil microbes that are also worth considering to be combined with the use of mealworms in PS waste biodegradation are fungi. Rhizopus oryzae, Aspergillus terreus and Phanerochaete chrysosporium are examples of soil inhabitants fungi that were able to colonize polystyrene film surface for a quite period of time without any other carbon source (Atiq, 2011).

\section{Conclusion}

The findings of this study show that PS foam does not have a lethal effect on the mealworms, but is clearly can not equate, moreover to surpass, the productivity effects of standard diets especially yeasts. It is inferred that the PS foam is not worthy feasible to be used as economical feeds in mealworms cultivation. Mealworms fed with PS foam feeds showed a low rate of growth and development of larvae, pupae and imago and make the imago produce a lower number of eggs. Between the two types of PS waste, XPS foam provides less productivity measures compared to EPS foam feeds. However, given that PS foam feeds can maintain the insects life and produce eggs, the use of mealworms in PS waste degradation is still worth considering.

\section{Acknowledgement}

We would like to thank Deasy Vidya Carolina Manullang and Rahmawati who helped us to take care the stock mealworms.

\section{Funding Information}

No necessary funding information.

\section{Author's Contributions}

Nismah Nukmal: Designed the study, conduct data analysis and manuscript preparation.

Suratman Umar: Carrying out experiments and data analyses. responsible bioassay and developing manuscript.

Sheila Puspita Amanda: Responsible for collecting and preparing styrofoam feeds.

Mohammad Kanedi: Responsible for editing and finishing manuscript.

\section{Ethics}

This article is original and contains unpublished material. The corresponding author confirms that no ethical issues involved.

\section{References}

ACH, 2013. EPS Vs. XPS apples-to-apples comparison of rigid foam insulation. ACH Foam Technologies.

Asmita, K., T. Shubhamsingh and S.Tejashree, 2015. Isolation of plastic degrading micro-organisms from soil samples collected at various locations in Mumbai, India. Int. Res. J. Environ. Sci., 4: 77-85. 
Atiq, N., 2011. Biodegradability of synthetic plastics polystyrene and styrofoam by fungal isolates. $\mathrm{PhD}$ Thesis, Department of Microbiology, Quaid-i-Azam University, Islamabad.

ATSDR, 1992. Agency For Toxic Substances and Disease Registry (ATSDR). Toxicological Profile For Styrene, U.S. Public Health Service, U.S. Department of Health And Human Services, Atlanta, GA.

Becher, P.G., G. Flick, E. Rozpędowska, A. Schmidt and A. Hagman et al., 2012. Yeast, not fruit volatiles mediate Drosophila melanogaster attraction, oviposition and development. Funct. Ecol., 26: 822-828. DOI: 10.1111/j.1365-2435.2012.02006.x

CIWMB, 2004. California Integrated Waste Management Board (CIWMB). Use and Disposal of Polystyrene in California.

Derrick, S., 2010. Polystyrene recycling. Green Manufacturing Initiative, Western Michigan University, College of Engineering and Applied Science Manufacturing Research Center, USA.

Genta, F.A., R.J. Dillon, W.R. Terra and C. Ferreira, 2006. Potential role for gut microbiota in cell wall digestion and glucoside detoxification in Tenebrio molitor larvae. J Insect Physiol., 52: 593-601.

Gibson, C.M. and M.S. Hunter, 2010. Extraordinarily widespread and fantastically complex: Comparative biology of endosymbiotic bacterial and fungal mutualists of insects. Ecol. Lett., 13: 23-234. DOI: $10.1111 /$ j.1461-0248.2009.01416.x

Graham, M.S., 2015. Specifying polystyrene: ASTM International product standard provides guidance. Tech Today. www.professionalroofing.net

Grau, T., A. Vilcinskas and G. Joop, 2017. Sustainable farming of the mealworm Tenebrio molitor for the production of food and feed. Z Naturforsch C., 72: 337-349. DOI: 10.1515/znc-2017-0033

Jung, J., A. Heo, W.Y. Park, Y.J. Kim and H. Koh et al., 2014. Gut microbiota of Tenebrio molitor and their response to environmental change. Microbiol. Biotechnol., 24: 888-897. PMID: 24861345

Kale, S.K., A.G. Deshmukh, M.S. Dudhare and V.B. Patil, 2015. Microbial degradation of plastic: A review. J. Biochem. Tech., 6: 952-961.

Lacounty Gove, 2008. An overview of expanded polystyrene food containers in los angeles county. County of Los Angeles.

Morales-Ramos, J.A., M.G. Rojas, S. Kay, D.I. ShapiroIIan and W.L. Tedders, 2012. Impact of adult weight, density and age on reproduction of Tenebrio molitor (Coleoptera: Tenebrionidae). J. Entomol. Sci., 47: 208-220. DOI: 10.18474/0749-8004-47.3.208
Park, Y.K., Y.C. Choi, Y.B. Lee, S.H. Lee and J.S. Lee et al., 2012. Fecundity, life span, developmental periods and pupal weight of Tenebrio molitor L. (Coleoptera: Tenebrionidae). J. Sericultural Entomol. Sci.., 50: 126-132. DOI: $10.7852 /$ jses.2012.50.2.126

Roeder, K.A., I. Kuriachan, S.B. Vinson and S.T. Behmer, 2010. Evaluation of a microbial inhibitor in artificial diets of a generalist caterpillar, Heliothis virescens. J. Insect Sci., 10: 1-12. DOI: $10.1673 / 031.010 .19701$

Rojas-Jiménez, K. and M. Hernández, 2015. Isolation of fungi and bacteria associated with the guts of tropical wood-feeding coleoptera and determination of their lignocellulolytic activities. Int. J. Microbiol., 2015: 1-12. DOI: 10.1155/2015/285018.

Sitompul, R.H., 2006. Pertumbuhan dan konversi pakan ulat tepung (Tenebrio molitor L.) pada kombinasi pakan komersial dengan Dedak Padi. Onggok dan Pollard. IPB Sci. Repository.

Sreeramoju, P., M.S.K. Prasad and V. Lakshmipathi, 2016. Complete study of life cycle of tribolium castaneum and its weight variations in the developing stages. Int. J. Plant Anim. Environ. Sci., 6: 95-100.

Vega, F.E. and P.F. Dowd, 2005. The role of yeasts as insect endosymbionts. Insect-Fungal Assocations: Ecology and Evolution, Oxford University Press, United Kingdom.

Wang, Y. and Y. Zhang, 2015. Investigation of gutassociated bacteria in Tenebrio molitor (Coleoptera: Tenebrionidae) larvae using culture-dependent and DGGE methods. Annals Entomol. Society Am., 108: 941-949. DOI: 10.1093/aesa/sav079

WHO, 1987. IARC monographs on the evaluation of carcinogenic risks to humans. Overall Evaluations of Carcinogenicity: An Updating of IARC Monographs Volumes 1 to 42. Supplement 7. World Health Organization. Lyon. France.

WHO, 2000. 2,2-dichloro-1,1,1-trifluoroethane (HCFC123). Concise International Chemical Assessment Document 23, World Health Organization, Geneva.

Yang, Y., J. Yang, W.M. Wu, J. Zhao and Y. Song et al., 2015a. Biodegradation and mineralization of polystyrene by plastic-eating mealworms: Part 1 . chemical and physical characterization and isotopic tests. Environ. Sci. Technol., 49: 12080-12086. DOI: 10.1021/acs.est.5b02661

Yang, Y., J. Yang, W.M. Wu, J. Zhao and Y. Song et al., 2015b. Biodegradation and mineralization of polystyrene by plastic-eating mealworms: Part 2. role of gut microorganisms. Environ. Sci. Technol., 49: 12087-12093. DOI: 10.1021/acs.est.5b02663 